\title{
English as Medium of Instruction for Subject Courses in Tertiary Education: Lessons Learned from Thai Undergraduate Students
}

\author{
Pennee Kantavong ${ }^{1}$ \\ ${ }^{1}$ College of Local Administration, Khon Kaen University, Thailand \\ Correspondence: Pennee Kantavong, College of Local Administration, Khon Kaen University, Thailand. E-mail: \\ Pennee@kku.ac.th
}

Received: June 25, $2015 \quad$ Accepted: October 8, $2015 \quad$ Online Published: November 20, 2015
$\begin{aligned} & \text { doi:10.5539/ass.v11n27p84 } \\ & \text { URL: http://dx.doi.org/10.5539/ass.v11n27p84 }\end{aligned}$

\begin{abstract}
This is a classroom action research project conducted in an undergraduate course using English as a medium of instruction. The objectives were to identify good approaches to developing students' capacity to understand English and to promote a positive attitude towards the English language. Two cycles of action with various instructional approaches were administered. By the end of the action research cycles, $80 \%$ of the students showed a positive opinion towards learning with English. During the sessions, $20 \%$ of the students needed help regularly. The cooperative learning model was found to be one of the more effective leaning activities, stimulating students to develop their learning and relieve their tensions in using a foreign language. The reflections from students revealed that the learning approaches employed in this study helped students to develop both their English comprehension in the written material and a positive attitude towards learning in English.
\end{abstract}

Keywords: English as medium of instruction, teaching subject courses, tertiary education

\section{Background}

There has been great demand for the development of English communication and its use as a comprehensive classroom language throughout the Asia Pacific region including Thailand, where English is considered to be the dominant foreign language. However, the level of English language competence among Thai people, even university students, is still very poor. This may be because there is very little use of English in the education environment. Students are required to study English during their compulsory education for at least six years. At a tertiary level there are at least 12 credits required for every student. However, based on the English Proficiency Index of 2013, Thailand ranked 55 $5^{\text {th }}$ out of 60 countries in English competence. And in 2014 Thailand only showed slight improvement. Thailand ranked 48 out of 65 countries; still in the bottom ranks (Education First, 2014; Education First, 2015). This shows that the English level of Thai students remain low. In general, Thai students do not see any need to pay much attention to their English instruction. Thai students begin their English class at 7 years old and continue studying about three to four hours a week through their 12 grades (16 years old).The pedagogy used is mainly text and explanation with Thai teachers. Very few schools had foreign teachers. But, during the past five years, the government has launched a policy to promote the English ability of Thai students so they can be effective citizens when Thailand fully joins the ASEAN (the Association of Southeast Asian Nations) community in the year 2015.

To be in line with the government policy, every educational institution promotes English development projects. Khon Kaen University also tries to prepare the students in English for communication by providing an English environment for students to experience and to motivate them to learn the language. Every faculty should have at least one subject per semester that uses English as a tool of instruction.

The aim of this study was to identify an optimal approach to helping undergraduate students to improve their English skills by learning a subject with English as a medium of instruction. The desired outcome from the instructional approaches tested was a positive attitude towards the English language. This was made more difficult since the students had differing levels of English abilities and they were not highly motivated to learning in English.

\section{Literature Review}

\subsection{Instructional Approaches}

Biggs (1990) pointed out that students usually began with the intention either to focus on the actual words used 
by the author or to focus on the author's meaning (the concept addressed in the text). The former was said to be a surface approach and the latter a deep approach. Biggs also suggested two important components in a student's relationship to academic learning. They are the student's motives for learning and the strategies for going about learning. One learning approach that has been used in teaching includes partners in learning; it is believed that working together as pair or group would provide opportunities for students to coach one another as they develop learning skills. This cooperative learning will generally provide more motivation than do individual approaches. The members of the group learn from each other. Cooperative learning also increases self-esteem for students. The students feel that they are respected and cared for by the others. The students with higher achievement also learn to share and interact with their friends. (Joyce, Weil, \& Showers, 1992).

As for reading English comprehension, Survey, Read, Recite, Review, and Reflect (SQ4R), an approach for English teaching technique, proposed by Huitt (2006); later altered by Slavin (2006) to Preview, Read, Recite, Review, and Reflect (PQ4R) is recommended for one of the effective methods.

The PQ4R steps can be summarized as:

I. Pre-Reading:

a. Preview (P) - this step helps students to skim the text.

b. Question $(\mathrm{Q})$ - the students try to propose questions from what they read. The teacher has to be a facilitator for the students.

II. While-reading:

a. Read $\left(\mathrm{R}_{1}\right)$-the students read in details in order to find the answers from the questions developed in Ib.

b. Recite $\left(\mathrm{R}_{2}\right)$ - the students describe and form concepts from the text they read.

III. Post-reading:

a. Review $\left(\mathrm{R}_{3}\right)$-the students skim the text for the main concepts again.

b. Reflect $\left(\mathrm{R}_{4}\right)$-the students reflect on their understanding by connecting the present information to their prior knowledge or to present their understanding in some other form.

When planning the instruction, the instructor needs to focus on the goals of her teaching. Ralph Tyler's "Planning Backward" was presented in Tomlinson \& Mc Tighe (2006) in three main stages.

"Stage I: identify desired results what should student know, understand and be able to do? Understanding? ... What essential questions will be explored?

Stage II: Determine acceptable evidence. How will we know whether students have achieved the desired results?

Stage III: Plan learning, experience and instruction. What enabling knowledge and skills will students need to perform effectively and achieve desired results?" pp. 27-28

\subsection{Research in English as a Medium of Instruction in Asia}

English as a medium of instruction has been implemented in various countries in addition to the Asia and Pacific region. Killickaya (2000) surveyed the attitudes of 100 instructors towards the use of English in universities in Turkey. It was found that the instructors who used English and Turkish as medium of instruction were concerned about, among other things: learning resources provided in Turkish and English; the proficiency level of the students; and student participation. The instructors also reported that differing needs of individual students should be taken into consideration. Some studies, such as Kirkpatrick (2011), reported that a move towards increasing the use of English as medium of instruction at the university level had been launched in China in2001. He noted that the leader of China expressed his view that English would help China to be able to exchange ideas with the rest of the world. In Japan, internationalization has been seen as an opportunity to share their cultural values to the rest of the world. Implementation of these methods were also found in countries where English is an official second or foreign language.

Wong (2010) conducted longitudinal action research to investigate the effectiveness of using English as the sole medium of instruction in English classes. The study was administered in Hong Kong University. The study found that the more English the student spoke in class, the more confident they became with it. However, regarding the class in which Cantonese was allowed, Wong noted that...

"First-language sometimes helps better understanding, especially teacher needed to clarify some complicated concepts". It is also "time-consuming to using English to explain a simple vocabulary which 
in fact can be done within a second of Cantonese ..."p. 126

Some studies pointed out that second language learner were more successful academically when they first developed the concepts and learning in their native language (Krashen \& Biber, 1988; Willing 1985 cited in Wong, 2010, p. 120).MacWhinney (cited in Dixon et al., 2012) proposed a unified model of L1 and L2 acquisition and concluded that...

"L2 learners acquire new mappings of sound to meaning based on the L1 system.

As learners' $L 2$ proficiency increases, the dependence of L2 decreases" $p .35$

Chang (2010) evaluated the implementation of English as the medium of instruction for content course for undergraduate students. It was found that the students did not think that they had a high level of comprehension in their lectures. But the students were of the opinion that English instruction helped them improve their English language proficiency. In the neighboring country of Vietnam, Manh (2012) studied the usage of English as a medium of instruction at a higher education institution. Manh reported that by 2015 about $20 \%$ of universities in Vietnam would begin using English as a medium of instruction in certain subjects. The goal is to produce a future labor force with qualified professional knowledge and foreign-language competence to meet the requirements of the current era. Kagwesage (2012) investigated students' thoughts on the current use of English as the sole medium of instruction in Rwandan higher education. She reported that the students face different challenges and difficulties in using English in their academic activities, since students were provided an English medium while their English proficiency did not match the demands of their academic work. She also pointed out that collaboration and peer support should be encouraged in order to enhance processes of learning.

\section{Research Procedures}

The research design was an action research based on Kemmis \& McTaggart (1982). The benefits of action research design include: 1) the outcomes can be used for learning and teaching development; 2) the findings are used as a guideline for enhancing students' capacity and to provide information for further development for learning and teaching effectiveness; and 3) the design provides the researcher with the time to review their ongoing lessons and make adjustments based on input receive from the students and the empirical measurements. Thus, the students have real input in the lesson plan development.

The target group was a class of 63 third-year undergraduate students majoring in Public Administration who enrolled in the "Education Management in Local Government" course in the College of Local Administration in Khon Kaen University, Thailand. These students had studied four compulsory English courses during their previous semesters. The last course was "English for Public Administration." The students' grades from that course were used as a baseline to create the learning groups. Their English ability level ranged from low to high (19 students scored about $55 \%$ and 11 students scored about $75-85 \%$ respectively). All the rest of the students were at medium level (60-70\%).

Using English as a medium of instruction in the course was aimed at developing reading capacity and motivating students to focus more on English. In order to establish a pleasant learning environment, the students were assigned to twelve groups of five or six students. In each group there was at least one high- and one low-performance student. This way, every group consisted of students of different abilities.

A backward planning design following the three stages presented in Tomlinson and McTighe (2006) was selected to carry out the classroom activities. In stage three of the design template learning plan, the combination of a learning model modified from the CRIC (Co-operative Integrated reading and Composition) and the PQ4R (Preview, Question, Read, Recite, Review and Reflect) by Huitt (2006) and Slavin (2006) was used as one of a guideline approaches for organizing leaning activities

The instructional design was conducted for six weeks under the procedure of action research within three-hour sessions. The empirical measurements were derived from observation, discussion, reflection, class assignments and presentation. The information obtained was used to analyze the learning and teaching activities and make adjustments to the subsequent sessions. The feedback and reflection also provided guidelines for students and teacher improvement. The student assignments, presentation and reflections were recorded and analyzed for instructional modification and for the research report.

Intervention procedures based on backward planning design started the session by identifying the desired results with guideline questions such as:

"What should students know, understand, and be able to do?"

"What essential questions should be answered?" 
The second stage is to determine an acceptable range of answers based on the preliminary questions, so the researcher had to consider the assessment criteria in advance. The third stage is planning learning experience and instruction. The goal of this stage is to make the learning and teaching effective and productive for students. The teaching approaches used in this study were a combination of cooperative learning and the PQ4R technique. With this combination, the low-performance students could learn from their peers and did not have to struggle in their study alone.

The first session was primarily using the first language, Thai, for instruction. The class began with course syllabus explanation which informed the class about rules, tasks, work assignments and expected outcomes. Students were assigned to a group and a handout with English text was provided. The students were asked to reflect on their learning experiences and record their thoughts in their notebooks.

\section{Outcome}

The Classroom Action research outcome can be presented as follow:

The first cycle: This cycle included one session of three hours.

The students' reflections after the first session were that they became tense when they saw the handout, which was the extract from the English text book. The PQ4R technique did not materialize as planned. The teacher had to adjust the method of teaching by having the whole class reading out loud then she asked students to look for the difficult words on the Internet. The teacher also had to help translate phrases and explain the meaning to students. The students had a hard time summarizing the concept in English.

The second cycle: This cycle included two sessions of three hours each.

The reflections from the class after the first cycle provided information for the teacher to adjust the second cycle by providing list of difficult words with the meaning. As for the step of asking and answering questions, the researcher had to change the approach to allow students to present their answers in the form of a mind map or diagram instead of writing sentences.

In session two of the cycle two, the learning activities were the same as the first session of this cycle. It was observed that the students were more relaxed than in the previous two sessions. This was confirmed in the reflections from the class that showed that 80 percent of the students felt more relaxed and enjoyed the class, whereas 20 percent still felt a degree of tension. The adjustments made for the two sessions in the second cycle included modifying the handout and making some connections to the students' previous knowledge. The students were happy with the adjustments of the learning activities, especially when they could conclude their understanding through a mind map or diagram.

"Writing long paragraph in English is very difficult. But when we can conclude our concepts by mind map or diagram, we think we can do it better." (Feedback from the students)

\section{Lessons Learned}

This action research had a strong point in its lesson planning where the researcher/teacher planned her teaching and learning activities carefully in order to reach the desired outcome. However, the implementation of the PQ4R technique seemed not to be as effective in this study. It was observed that when the students had to learn the subject with English text, they had to adjust to accommodate two tasks: the content of the subject and difficult words and structure. In PQ4R procedure, students were supposed to reflect on what they had read and spoken. However, with the limitations of their English skills, they could not adequately perform this task. When the task was adjusted to other forms of reflective review of what they had read and presented with a mind map or diagram, the students performed well. Another point is that the use of Backward Instructional Planning Design requires students to act more than teachers do. In every session, the students had to present their assignment in front of the class or perform their tasks in groups. The students were familiar with listening from a lecture and reading the PowerPoint, but this teaching experience encouraged students to think and evaluate for themselves in terms of what they had learned, understood or not understood. The research design also provided a channel for them to reflect based on the PQ4R model. At the same time, Thai language, which is the student's first language, was allowed. The previous research pointed out that the students would be more successful academically when they develop concepts and learn in their native language. This means that the first language helps better understanding Wong (2010). This was evident in the present study, where it was observed that the students had to mix the L1 with English all the time.

"When we are in the group we have to discuss in Thai, it helps us to understand clearer."

"We feel that we can read English and understand concepts when key vocabulary was provided." 


\section{(Reflections from the students)}

In order to provide a pleasant learning environment and encourage students to try to use English, the imperfect English was also accepted.

In the sessions, the teacher asked each group of students to propose questions from the text. The teacher collected all the questions and put them in the correct form. All the modified questions were shown on the board. The students in the group that proposed the question took turns reading their questions, one group at a time, and asked students from different groups to answer. Every student in the class had to pay attention and considered if the answer was correct.

It was found that the various approaches were needed in order to cope with the problems of teaching the class with different English abilities students. The classroom action research opened the opportunity for the teacher to modified and adjust the instructional approaches to accommodate the learning situation all the period of the course.

So at the end of the six week learning the student felt their own improvement even not remarkable great but they improved their English learning motivation. The reflection showed that 37 percent of students said that they were happy with the class. They learn more English. They could understand what they read, could make correct pronunciation and would keep on studying English. Thirty percent of them said that they feel confidence in reading English aloud. Reflection from high English ability students were below:

"If we have to study subject course in English, we really need help with vocabulary for getting better understanding."

"We feel that we have learned more vocabulary and can cope with the paragraph in text. The mind map and diagram presentation was good guideline for our presentation, when we have to present in front of the class."

It can be concluded that the use of English as a medium of instruction in a subject course can develop students' English comprehension and lead to a positive attitude toward learning in English. This may be because while implementing the instruction with the lesson planning and the combination of instructional model, the researcher based her instructional approach on the consideration of time on task, content coverage, academic successes and effective feedback, which were the four elements of effective instruction pointed out by Kindervatter, Wilen \&Ishler (1988). However, the reflections showed that five percent of the students said that they felt far behind their peers.

"We feel very tense when we see the handout in English. We received help from friends but still we found that it was very difficult for us. Anyway we will try even we are so far behind." (Reflection from 5\% low ability students)

The above reflection agrees with Kagwesage (2012), who reported that the students who were taught with English as medium of instruction in academic courses faced different challenges and difficulties in using English in academic activities, so the collaboration and peer support could be used in order to enhance the processes of learning. In the present study, the English ability of most of students $(80 \%)$ did not match the demands of the academic work. The group activities and peer support were the main approaches to alleviating some of this problem. It was also observed that the lowest five percent was even in the very tough situation. Chang (2010) also found that the students reflected that they did not have very high comprehension in their lectures. However, in this present study, lecture was not the main avenue of instruction. The students worked in groups with the handout and follow-up activities, so they could grasp the concept via the Thai language with their friends' help.

It should be pointed out that English level of students in the class may be the main issue that should be developed prior to using English as a medium of instruction. In this study the researcher was well aware of the different English abilities of the learners. However, due to the large class size and the course content, the teaching methods could not be managed much differently.

\section{Conclusion and Suggestion}

The classroom action research was conducted with a class of 63 undergraduate students. English was used a medium of instruction in a subject course. The instruction was based on backward planning design and, in the last stage of each lesson plan; the PQ4R teaching model was used in to stimulate students to practice active learning. After the first cycle of the action research, the learning activities were modified to accommodate the students' needs and English abilities. By the end of the second cycle, it was found that $80 \%$ of students showed a positive attitude towards learning in English. The cooperative learning model, which was used as a tool for the 
preceding learning activities, provided strong support for a good learning environment for the diverse English learning abilities in the class. In summary, when English as medium of instruction was implemented, well-planned instructional approaches and varied instructional models were keys to success. The lessons learned for future class development are: 1) In a lesson plan, the teaching technique for English learning should be taken into consideration; 2) Various approaches of instructional models, such as cooperative learning, PQ4R and lesson planning based on backward planning, were good tools for the learning effectiveness; and 3) There should be special assignments to help the students with low English competency. This may be because the researchers overlooked the teaching techniques for foreign language teaching which should have been implemented, along with other techniques such as songs and games, which would have reduced the pressure for the low performance students.

\section{References}

Biggs, J. B. (1990). Effects of language medium of instruction on approaches to learning. Educational Research Journal, 5, 18-28.

Brophy, J., \& Good, T. L. (1986). Teacher behavior and student achievement. In M. Writtrock (Ed.), Handbook of Research on Teaching. New York: Macmillan.

Dixon, L. Q., Zhao, J., Shin, J. Y., \& associates. (2012). What we know about second language acquisition: A synthesis from four perspectives. Review of Educational Research, 82(1), 5-60.

Education First. (2014). Retrieved October 2015, from http://www.ef.co.th/epi/

Education First. (2015). Retrieved September 2015, from http://www.ef.co.th/epi/

Huitt, J. B. (2006). Educational psychology interactive: Methods ofstudy. Retrieved September 2013, from http://edpsyinteractive.org/topics/cogsys/sq4r.html

Joyce, B., Weil, M., \& Showers, B. (1992). Models of teaching. Boston: Allyn and Bacon.

Kagwesage, A. M. (2012). Student's reflection on the current use of English as the sole medium of instruction in Rwanda higher education. International Journal for the Scholarship of Teaching and Learning, 6(2), 1-14. Retrieved from http://digitalcommons.Georgiasouthern.edu/ij-soth/vol.6/iss2/18

Kemmis, S., \& McTaggart, R. (1982). The action research planner. Australia: Deakin University Press.

Killickaya, F. (2000, November 6). Instructors' attitudes towards English-medium instruction in Turkey. Humanizinglanguage teaching, 8(6).

Kindsvatter, R., Wilem, W., \& Ishler, M. (1988). Dynamics of effective teaching. New Jersey: Prentice Hall.

Kirkpatrick, A. (2011). Internationalization or Englishization? Medium of instruction in today's universities. Hong Kong Centre for Government and Citizenship: Hong Kong Institute of Education. Working Paper Series No. 2011/003.

Krashen, S., \& Biher, D. (1988). On course: Bilingual education succession California. Sacramento, CA: California Association for Bilingual Education.

Manh, L. D. (2012). English as a medium of instruction in Asian universities: The case of Vietnam. Language Education in Asia, 3, 263-267.

Sebatane, E. M. (1994). Enhancement of teacher capacities and capabilities in echo set-based assessment: Lesotho experience. Assessment in Education, 1(2), 223-234.

Slavin, R. E. (2006). Educational psychology: Theory and practice (8th ed.). Upper Saddle River, NJ: Pearson Higher Education. Retrieved October 2015, from http://online.sfsu.edu/-foreman/itec/finalprojects/ danabayer/studyskill/pq4r.html

Tomlinson, C. A., \& McTighe, J. (2006). Integrating differentiated instruction understanding by design. USA: Alexandria Virginia.

Wong, R. M. H. (2010). The Effective of using English as the sole medium of instruction in English classes: Student responses and improved English proficiency. Porta Linguarum, 13, 119-130.

\section{Copyrights}

Copyright for this article is retained by the author (s), with first publication rights granted to the journal.

This is an open-access article distributed under the terms and conditions of the Creative Commons Attribution license (http://creativecommons.org/licenses/by/3.0/). 